\title{
Corrigendum to "Prior to Conception: The Role of an Acupuncture Protocol in Improving Women's Reproductive Functioning Assessed by a Pilot Pragmatic Randomised Controlled Trial"
}

\author{
Suzanne Cochrane (iD, ${ }^{1}$ Caroline A. Smith (D), \\ Alphia Possamai-Inesedy, ${ }^{3}$ and Alan Bensoussan $\left(\mathbb{D}^{2}\right.$ \\ ${ }^{1}$ School of Science \& Health, Western Sydney University, Locked Bag 1797, Penrith, NSW 2751, Australia \\ ${ }^{2}$ National Institute of Complementary Medicine, Western Sydney University, Locked Bag 1797, Penrith, NSW 2751, Australia \\ ${ }^{3}$ School of Social Science \& Psychology, Western Sydney University, Locked Bag 1797, Penrith, NSW 2751, Australia \\ Correspondence should be addressed to Caroline A. Smith; caroline.smith@westernsydney.edu.au \\ Received 12 February 2017; Accepted 19 March 2018; Published 2 May 2018 \\ Copyright (C) 2018 Suzanne Cochrane et al. This is an open access article distributed under the Creative Commons Attribution \\ License, which permits unrestricted use, distribution, and reproduction in any medium, provided the original work is properly \\ cited.
}

In the article titled "Prior to Conception: The Role of an Acupuncture Protocol in Improving Women's Reproductive Functioning Assessed by a Pilot Pragmatic Randomised Controlled Trial" [1], the Conflicts of Interest section should read as follows:

CompleMED, a precursor of the National Institute of Complementary Medicine, where Professor Caroline A. Smith and Professor Alan Bensoussan are based as researchers, received a donation in 2010 of $\$ 20,000$ from the Acupuncture IVF Support Pty Ltd. This donation was untied and applied towards other unrelated research.

\section{References}

[1] S. Cochrane, C. A. Smith, A. Possamai-Inesedy, and A. Bensoussan, "Prior to Conception: The Role of an Acupuncture Protocol in Improving Women's Reproductive Functioning Assessed by a Pilot Pragmatic Randomised Controlled Trial," Evidence-Based Complementary and Alternative Medicine, vol. 2016, Article ID 3587569, 11 pages, 2016. 


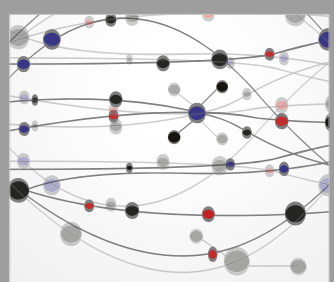

The Scientific World Journal
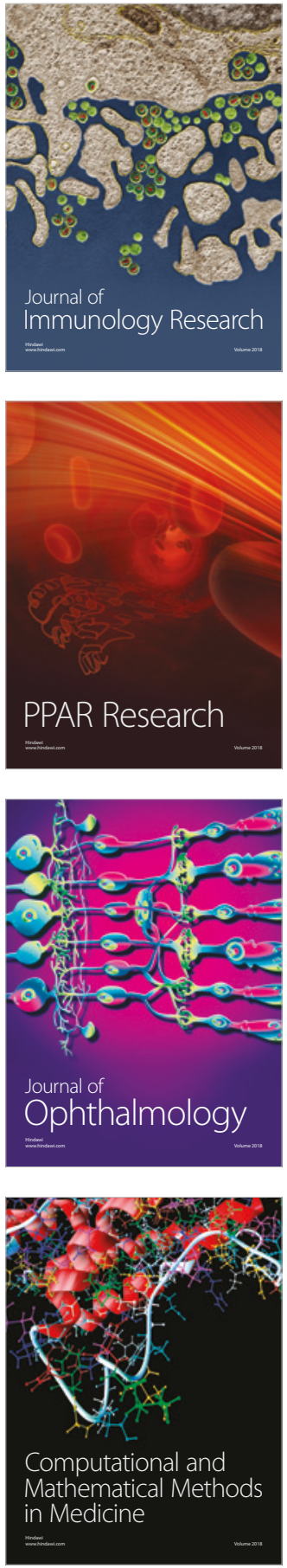

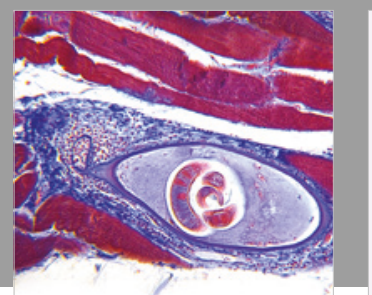

Gastroenterology Research and Practice

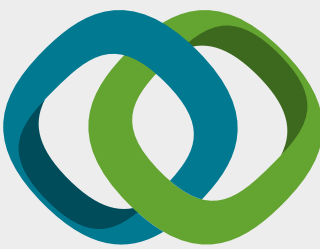

\section{Hindawi}

Submit your manuscripts at

www.hindawi.com
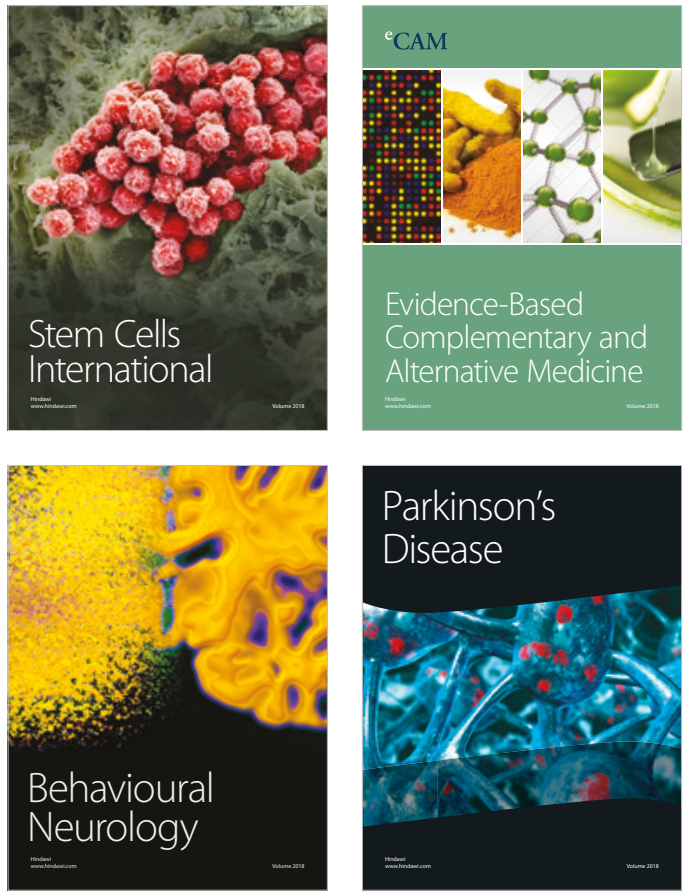

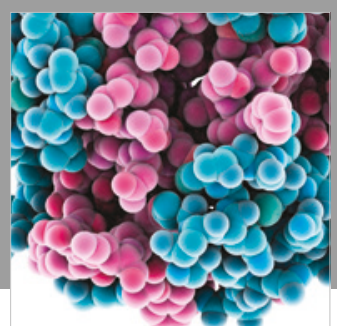

ournal of

Diabetes Research

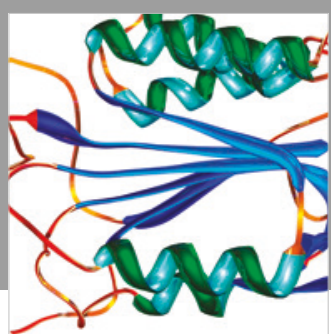

Disease Markers
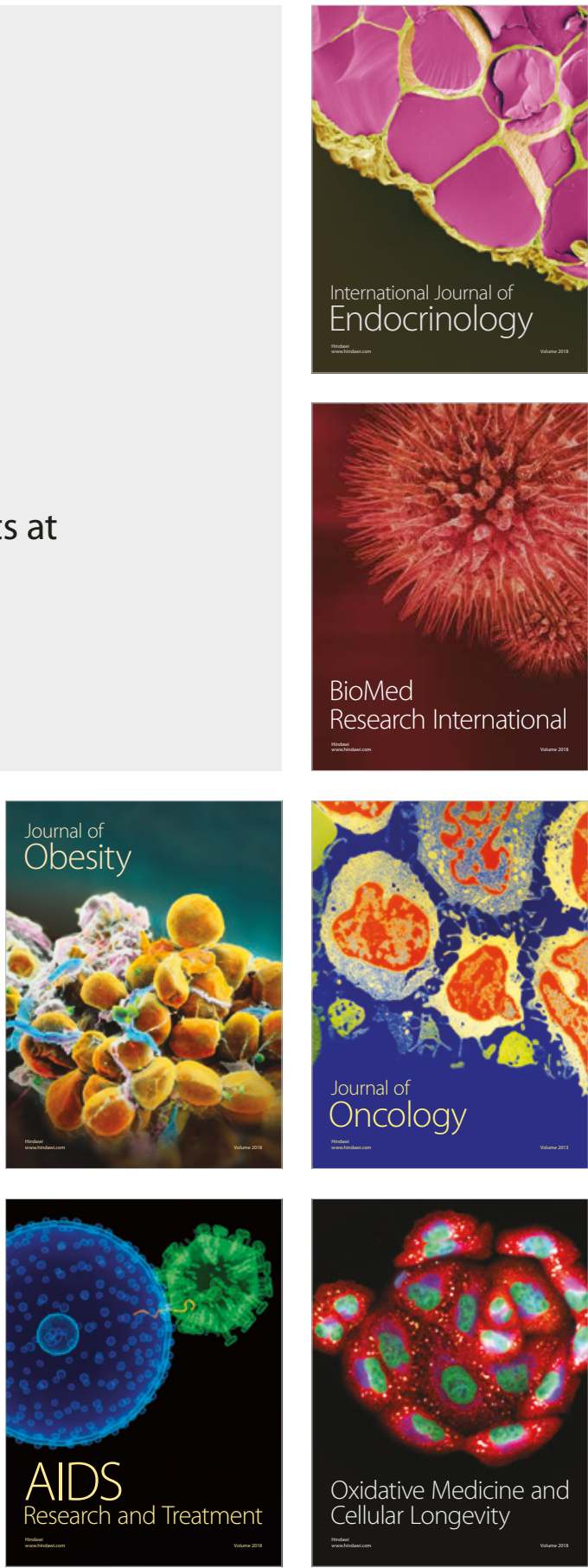